\title{
Electrochemical Modification of a Graphite Platform for a Solid Sampling Electrothermal Atomic Absorption Spectrometry of Mercury
}

\author{
Rostislav Červenka, Hana Zelinková, Marie Konečná, and Josef KoMÁREK ${ }^{\dagger}$ \\ Department of Chemistry, Faculty of Science, Masaryk University, Kotlářská 2, Brno 611 37, Czech Republic
}

\begin{abstract}
An electrodeposited palladium and iridium/gold mixture has been investigated as a chemical modifier for mercury determination in environmental samples by solid sampling electrothermal atomic absorption spectrometry. Electrochemical procedures of platform surface modification performed in a cell with $20 \mathrm{ml}$ of solution, and in a drop of modifier solution have been optimized. Simple electrolysis in a drop was found to be the most consistent, taking the reproducibility as the major criterion. A total mass of $250 \mu \mathrm{g}$ of electrodeposited palladium or an iridium/gold mixture was used. The lifetime of 60-70 firings for a deposited iridium/gold mixture was smaller than that for palladium with a lifetime of 100 - 120 firings. The detection limit was $120 \mathrm{pg} \mathrm{Hg}$. Different sample masses of between 0.1 and $10 \mathrm{mg}$ were weighed into modified platforms according to the mercury content. The results obtained for mercury in environmental samples as soils, sediments and plant, using solid sampling and calibration against aqueous standards stabilized by potassium permanganate, were in good agreement with those achieved by using the thermal deposition of modifiers and with measurements by pyrolysis atomic absorption spectrometry with gold amalgamation.
\end{abstract}

(Received March 10, 2010; Accepted July 1, 2010; Published September 10, 2010)

\section{Introduction}

Mercury and its compounds are trace contaminants in all environmental compartments, highly toxic with high volatility and an ability of bioaccumulation. Volcanic activity, combustion of coal and other human activities have led to the emission of mercury into air, water, sediments and soils. The analysis of soils and sediments can provide valuable information concerning the degree of contamination of the environment. Study of the mercury content in environmental samples is very important. ${ }^{1,2}$

One of the most widely used methods for the determination of mercury is cold vapor atomic absorption spectrometry (CVAAS). In CVAAS, the mercury present in the sample solution is reduced to the element. ${ }^{1,3,4}$ By CVAAS, the mercury vapor is liberated from the solution by the passage of a gas, and introduced into the optical path of the AA spectrometer. To increase the sensitivity of CVAAS, the preconcentration of mercury vapor onto a gold or gold/platinum trap, and its release by thermal desorption is used. ${ }^{1}$ For the analysis of solid samples, the conversion of the solid matrix into an aqueous form is necessary. This is achieved by heating the sample with concentrated acid at either atmospheric or elevated pressure using open or sealed vessels, respectively. A variety of acids have been proposed for the digestion and extraction of samples, such as aqua regia, nitric and sulfuric acids with or without the addition of hydrogen peroxide and hydrochloric acid. The dissolution step requires time, and there is a risk of analyte loss during any pretreatment. The possible error sources are

$\dagger$ To whom correspondence should be addressed.

E-mail: komarek@chemi.muni.cz volatilization and adsorption losses, sample contamination and increased blank values during the use of a large amount of reagents. ${ }^{1,3-5}$

Another approach is the combustion of a solid sample in an oxygen atmosphere, ${ }^{3,6}$ or in the presence of an air stream ${ }^{7}$ and the collection of produced mercury vapor on the surface of a gold amalgamator prior to its thermal release and determination. Reference materials, including rocks, soils, sediments and coal, were analyzed using sample masses in the range of $20-300 \mathrm{mg}$. The results of 33 samples, with one exception, were in agreement with the recommended values. ${ }^{6}$ This pyrolysis AAS approach with gold amalgamation is capable of sensitive $\mathrm{Hg}$ determination, although some drawbacks have also been pointed out, such as the lack of a background correction system, which may result in problems with possible interferences, especially for the analysis of samples with a high organic content. ${ }^{3}$

For the direct analysis of solid samples during the last years, the use of solid sampling electrothermal atomic absorption spectrometry (SS-ETAAS) has been reported., ${ }^{1,8-11}$ This method shows interesting advantages. Solid sampling requires a very small amount of a sample (usually a few milligrams), and little or no sample pretreatment. The absence of sample dilution increases the determination sensitivity and sample throughput.

The main problem in the determination of mercury by ETAAS is the high volatility of the element and its compounds. The thermal stabilization of mercury prior to its atomization is important for avoiding losses of the analyte. ${ }^{1,12}$ Due to the more pronounced volatility of mercury metal, several oxidizing agents, precipitants or complexing reagents, as hydrogen peroxide, permanganate, dichromate, sulfide, tellurium, dithizone, diethyldithiocarbamate, tetramethylendithiocarbamate, spherone thiol and others, were used to prevent the reduction of 
mercury compounds. ${ }^{1,2,12,13}$ One successful approach for the stabilization of mercury is the use of noble metals as modifiers. ${ }^{1,10,12,14,15}$ The modification of an atomizer surface with noble metals can be obtained by a thermal or electrochemical method. ${ }^{12}$ Palladium, gold, rhodium and iridium were investigated by solution analysis, and the gold/rhodium mixture and palladium alone, thermally reduced in a graphite tube, gave the best analytical sensitivity. ${ }^{12}$ Palladium as a chemical modifier and the standard addition method were used in the direct introduction of slurries into a graphite furnace. ${ }^{16,17}$ Calibration with slurry sampling was carried out by using aqueous standards when both silver nitrate and potassium permanganate were added to both the suspensions and aqueous standards. ${ }^{2}$ A determination was also possible by the addition of permanganate and palladium to the aqueous standards and slurries to stabilize mercury. ${ }^{18}$

Iridium, palladium, rhodium and ruthenium, thermally deposited onto the platform by SS-ETAAS, were investigated as modifiers for the determination of mercury; the use of palladium was found to be optimal. A loss-free determination of mercury in aqueous solutions after the addition of potassium permanganate made possible the use of aqueous standards for the direct analysis of solid samples. ${ }^{1}$ The direct solid sampling Zeeman atomic absorption spectrometric method with the use of platinum transport boats, and a specially designed nickel tube furnace permanently heated at a constant temperature of $1000^{\circ} \mathrm{C}$ was also applied. Certified reference materials were used for mercury calibration. ${ }^{8}$ The use of a permanent modifier simplifies the procedure compared to the addition of a modifier in solution to each sample aliquot. ${ }^{1,19}$ According to a study, ${ }^{9}$ the permanent chemical modifiers can be used for direct SS-ETAAS, despite the sample not being in intimate contact with the modifier. A straightforward procedure was proposed for the determination of mercury in biological materials using solid sampling and high-resolution continuum source electrothermal atomic absorption spectrometry (HR-CS-ETAAS) in a graphite tube with calibration against aqueous standards stabilized by potassium permanganate, with the elimination of the pyrolysis stage and without the use of any chemical modifiers of the platform surface. ${ }^{10}$

It was found that the electrodeposition of noble metals on a graphite surface significantly improves the performance in the presence of a corrosive matrix..$^{20,21}$ Noble metals stabilize the analyte and act as permanent modifiers via the formation of intercalation compounds in the subsurface layer of pyrographite. Penetration is more pronounced using electrodeposition, since this forces the transportation of noble metals into the subsurface domain of the graphite. ${ }^{21-23}$

The goal of this work was to utilize the advantages of an electrochemical modification of a graphite surface for mercury determination in environmental materials, such as soils, sediments and plant by using SS-ETAAS. Electrochemical procedures in cells and in drops for modifying the solid sampling (SS) platform surface were investigated and optimized. The use of aqueous standards with the addition of permanganate for the calibration was verified. The results obtained by using electrochemical modified SS platforms were compared with those by using a thermally modified SS platform and pyrolysis atomic absorption spectrometry with gold amalgamation.

\section{Experimental}

\section{Instrumentation}

A ZEEnit 650 atomic-absorption spectrometer (Analytik Jena,
Table 1 Temperature program for the determination of mercury

\begin{tabular}{lccc}
\hline \multicolumn{1}{c}{ Stage } & Temperature $/{ }^{\circ} \mathrm{C}$ & ${\text { Ramp } /{ }^{\circ} \mathrm{C} \mathrm{s}^{-1}}$ & Hold time $/ \mathrm{s}$ \\
\hline Drying & 90 & 30 & 15 \\
Pyrolysis & 200 & 30 & 40 \\
AZ $^{\mathrm{a}}$ & 200 & 0 & 6 \\
Atomization $^{\mathrm{b}}$ & 1100 & 1500 & 10 \\
Cleanout & 1700 & 200 & 4 \\
\hline
\end{tabular}

a. Auto zero.

b. Gas stop.

Germany) with a transversely heated graphite tube atomizer and a solid sampling system SSA $61 Z$ (Analytik Jena) was used for all measurements. The spectrometer was equipped with both a Zeeman-based and a deuterium background corrector. The magnetic field of an electromagnet was applied to the graphite atomizer by the 2-field mode, and the orientation of the magnetic field was transverse to the optical axis. Zeeman corrections were used throughout the work, and the deuterium device was used only for the construction of pyrolysis curves. A mercury hollow cathode lamp, operated at $4.5 \mathrm{~mA}$, was used as the radiation source. Measurements were performed in the peak area mode (integrated absorbance) at $253.7 \mathrm{~nm}$ using a spectral bandwidth of $0.5 \mathrm{~nm}$. SS graphite tubes without a dosing hole (Analytik Jena, Part No. 152:516.25) and SS graphite platforms (Analytik Jena, Part No. 407-152.023) were used throughout. The calculated integrated absorbance per $\mathrm{mg}$ of sample is introduced as the normalized absorbance. Aqueous solutions were pipetted manually onto the SS platform and introduced in the same way as the solid samples. The temperature program used for the determination of mercury is presented in Table 1.

For comparison purposes, the mercury contents in environmental materials were also determined by a pyrolysis AAS approach using the analyzer AMA 254 (Altec). The method is based on the thermal decomposition of a sample portion in a flow of oxygen, the capture of mercury by a gold amalgamator and measurements of the mercury vapor absorbance after thermal release from the amalgamator.

\section{Reagents and chemicals}

Calibration solutions of $\mathrm{Hg}$ (II) were prepared by dilution of the stock standard solution for mercury $\left(1.000 \pm 0.002 \mathrm{~g} \mathrm{l}^{-1} \mathrm{Hg}\right)$ in $2 \% \mathrm{HNO}_{3}$ (Analytika, Czech Republic) with $5 \%$ (v/v) nitric acid. For stabilization with potassium permanganate, a stock solution of $110 \mathrm{~g} \mathrm{l}^{-1} \mathrm{KMnO}_{4}$ (Merck) was added to the calibration solutions to a final concentration of $100 \mathrm{~g} \mathrm{l}^{-1}$. The $\mathrm{KMnO}_{4}$ was dissolved with the support of an ultrasonic bath.

A gold standard solution, Astasol containing $1000 \mathrm{mg} \mathrm{l}^{-1} \mathrm{Au}$ (Analytika, Czech Republic), and a palladium solution containing $10 \mathrm{~g} \mathrm{l}^{-1} \mathrm{Pd}$ (Merck, Darmstadt, Germany) were used. The iridium modifier solution $\left(500 \mathrm{mg} \mathrm{l}^{-1} \mathrm{Ir}\right.$ ) was obtained by the dissolution of iridium chloride in $10 \% \mathrm{HNO}_{3}$ (Merck).

The following environmental materials were investigated: certified reference materials (CRMs) estuarine sediment CC580, No. 0160 (European Commission DG JRC, IRMM, Geel, Belgium) and soil GBW 07405 (National Center for Standard Materials, Beijing, China), samples of soils I, II and plant Scirpus from the $\mathrm{Hg}$ polluted area.

The environmental materials were ground in a mill Fritsch Pulverisette 7 with balls from $\mathrm{Si}_{3} \mathrm{~N}_{4}$, and passed through a nylone sieve for a particle size of $\leq 56 \mu \mathrm{m}$. No impairment of the precision for real samples by using these particles was observed. Aliquots of samples of between 0.1 and $0.5 \mathrm{mg}$, 


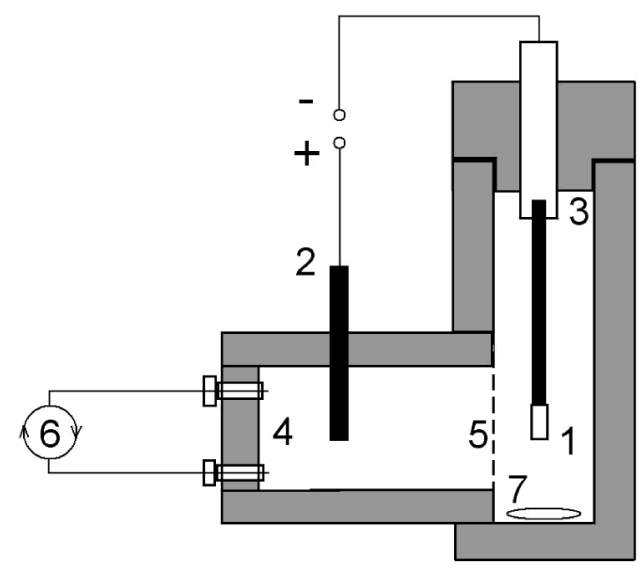

Fig. 1 Schematic diagram of the electrochemical cell: (1) graphite SS-platform, (2) graphite rod, (3) the part with electrolyzed solution, (4) the anodic part, (5) Nafion membrane, (6) peristaltic pump, (7) magnetic stirrer.

Table 2 Temperature program for thermal deposition of modifiers on the surface of SS platforms (according to study ${ }^{1}$ )

\begin{tabular}{lccc}
\hline \multicolumn{1}{c}{ Stage } & Temperature $/{ }^{\circ} \mathrm{C}$ & Ramp $^{\circ} \mathrm{C} \mathrm{s}^{-1}$ & Hold time $/ \mathrm{s}$ \\
\hline Drying & 90 & 30 & 15 \\
Pyrolysis & 250 & 20 & 35 \\
AZ $^{\mathrm{a}}$ & 250 & 0 & 6 \\
Atomization $^{\mathrm{b}}$ & 1000 & 1000 & 10 \\
Cleanout & 2000 & 200 & 5 \\
\hline
\end{tabular}

a. Auto zero.

b. Gas stop.

especially for soil I 2 - $6 \mathrm{mg}$ and CRM GBW 074052 - $10 \mathrm{mg}$, were weighed directly onto the SS platforms and inserted into a graphite tube. Before each weighing these ground samples were carefully stirred. CRM estuarine sediment CC580 was with respect to the $\mathrm{Hg}$ content 4-times diluted with gypsum. The residues of solid samples after atomization spill easily from the platform.

\section{Procedures}

Electrodeposition of modifiers in a stationary arrangement. A commercial SS platform served as a working electrode in a stationary electrochemical cell ${ }^{24}$ (Fig. 1). A graphite rod was used as a counter electrode. The cathodic space was separated from the anodic space by the cation-exchange membrane Nafion. Through the anodic space, a solution of $1 \mathrm{~mol} \mathrm{l}^{-1}$ nitric acid was circulated by using a flow rate of $2 \mathrm{ml} \mathrm{min}^{-1}$ with a PCR Labeco peristaltic pump. A volume of $20 \mathrm{ml}$ of an electrolyzed solution was stirred with an electromagnetic stirrer. The electrolyses of modifiers were performed under galvanostatic control by using a Radelkis $\mathrm{OH} 404$ potentiostat. The solution of each metal (Pd, Ir) or iridium/gold mixture was electrolyzed for $60 \mathrm{~min}$ by using a current of $5 \mathrm{~mA}$. The total amount of metals, or their mixture in the solution was $4 \mathrm{mg}$. After electrolysis the SS platform with a deposited modifier was rinsed with double-distilled water, and dried. Then, the temperature program given in Table 2 was applied. Before the determination of mercury, it was necessary to make 10 repetitive firings according to Table 1 (the thermal conditioning) for the attainment of constant results.

Electrodeposition of palladium from a drop of solution.

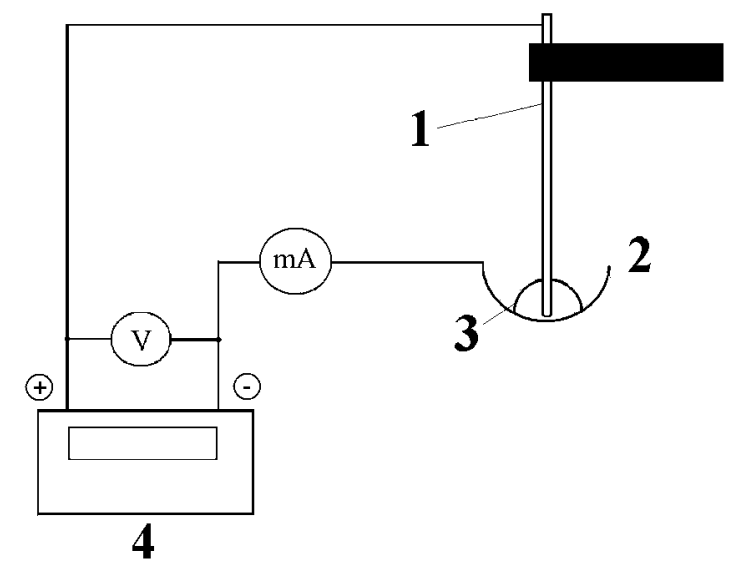

Fig. 2 Schematic diagram for the electrochemical deposition from drop: (1) Pt wire-anode, (2) SS platform-cathode, (3) modifier solution drop, (4) power supply.

A modifier was applied using 7 injections of $20 \mu \mathrm{l}$ of a solution $\left(2000 \mathrm{mg} \mathrm{l}^{-1} \mathrm{Pd}\right)$ onto the $\mathrm{SS}$ platform and consecutive electrodeposition stages. During electrodeposition, the inner surface of the graphite platform at its point of contact with the modifier solution served as the cathode and a Pt wire was used as the anode when immersed into the solution (Fig. 2). Palladium was electrolyzed from every drop at a current of $10 \mathrm{~mA}$ for $5 \mathrm{~min}$. After each electrodeposition, the depleted solution was emptied, and the surface of the SS platform was rinsed with water and dried. The SS platform was inserted into a graphite tube and the temperature program started according to Table 2. Then, thermal conditioning followed. The amount of Pd electrodeposited on the SS platform surface was calculated from the difference between the total and remaining amounts of $\mathrm{Pd}$ in the solution before and after electrolysis. The concentration of Pd in these solutions was determined by ETAAS with direct sampling into the graphite tube. During electrolysis $255 \mu \mathrm{g} \mathrm{Pd}$ was deposited. This procedure resulted from optimization of the electrodeposition conditions at 10 and $30 \mathrm{~mA}$ for $2-10 \mathrm{~min}$ and $200-2000 \mathrm{mg} \mathrm{l}^{-1} \mathrm{Pd}$ with respect to the low total time of deposition.

Electrodeposition of iridium/gold mixture from a drop of solution. A modifiers mixture was applied using 25 injections of $20 \mu \mathrm{l}$ of the mixture solution $\left(250 \mathrm{mg} \mathrm{l}^{-1} \mathrm{Ir}\right.$ and $250 \mathrm{mg} \mathrm{l}^{-1}$ $\mathrm{Au}$ ) onto the SS platform and consecutive electrodeposition stages. Electrodeposition from every drop of the modifier solution was performed at a current of $10 \mathrm{~mA}$ for $5 \mathrm{~min}$. After each electrodeposition, the depleted solution was emptied; then the surface of SS platform was rinsed with water and dried. The SS platform was inserted into a graphite tube, and the temperature program was started according to Table 2. Then, thermal conditioning followed. The amount of $\mathrm{Au}$ and $\mathrm{Ir}$ electrodeposited on the SS platform surface was calculated from the difference between the total and remaining amounts of $\mathrm{Au}$ and Ir in the solution before and after electrolysis. The concentration of $\mathrm{Au}$ in these solutions was determined by ETAAS with direct sampling after stabilization of the solutions with $0.1 \mathrm{~mol} \mathrm{l}^{-1} \mathrm{HCl}$ and $0.5 \mathrm{~g} \mathrm{l}^{-1} \quad \mathrm{NH}_{4} \mathrm{SCN}$, and the concentration of Ir was determined by inductively coupled plasma optical emission spectrometry. During electrolysis, $123 \mu \mathrm{g} \mathrm{Au}$ and $125 \mu \mathrm{g}$ Ir were deposited.

Thermal deposition of modifiers. A total mass of $250 \mu \mathrm{g}$ of modifiers (Pd, Ir) or $250 \mu \mathrm{g}$ iridium/gold mixture was applied using 25 injections of $20 \mu \mathrm{l}$ of the modifier solutions (500 $\mathrm{mg} \mathrm{l}^{-1}$ 
Table 3 Maximum pyrolysis temperatures for the determination of mercury in aqueous solution stabilized by potassium permanganate

\begin{tabular}{lccc}
\hline & \multicolumn{3}{c}{ Temperature $/{ }^{\circ} \mathrm{C}$} \\
\cline { 2 - 4 } Modifier & $\begin{array}{c}\text { Thermally } \\
\text { prepared }\end{array}$ & $\begin{array}{c}\text { Stationary } \\
\text { electrolysis }\end{array}$ & $\begin{array}{c}\text { Electrolysis } \\
\text { in drop }\end{array}$ \\
\hline $\mathrm{Pd}$ & 330 & 200 & 250 \\
$\mathrm{Ir}$ & 400 & 300 & - \\
$\mathrm{Ir}+\mathrm{Au}$ & 250 & 200 & 300 \\
\hline
\end{tabular}

Pd, $500 \mathrm{mg} \mathrm{l}^{-1} \mathrm{Ir}$ or mixture of $250 \mathrm{mg} \mathrm{l}^{-1} \mathrm{Ir}$ and $250 \mathrm{mg} \mathrm{l}^{-1}$ $\mathrm{Au})$. After each injection the modifier solution was dried and pyrolyzed according to the temperature program given in Table 2 to obtain the metal in its reduced form, and then thermal conditioning followed.

\section{Results and Discussion}

\section{Modification of the platform surface and aqueous calibration standards}

Aqueous calibration solutions were stabilized with the addition of $\mathrm{KMnO}_{4}$. For technical reasons only $3 \mu \mathrm{l}$ of a solution of $\mathrm{KMnO}_{4}$ with a concentration $\geq 10 \mathrm{~g} \mathrm{l}^{-1}$ was injected onto the SS platform. By the injection of a volume $>3 \mu$, a drop of solution with great viscosity superimposed inner space of the SS platform and the insertion of the SS platform into the graphite tube without any spill by using tweezers was impossible. For the optimal total amount, $0.3 \mathrm{mg}$ of $\mathrm{KMnO}_{4}$ onto the surface of the SS platform, a concentration of $100 \mathrm{~g} \mathrm{l}^{-1} \mathrm{KMnO}_{4}$ is required for $3 \mu \mathrm{l}$ of the solution. According to pyrolysis curves, the mercury species were stabilized to the pyrolysis temperatures given in Table 3. In both cases with electrodeposition and thermal deposition, the sensitivity of mercury determination was for iridium lower than that for palladium alone, or the iridium/gold mixture. For Pd, Ir and iridium/gold mixtures prepared using stationary electrodeposition was showed worse reproducibility. This is connected with the small reproducibility of the electrochemical coating of the platform dip with respect to the platform shape and the stirring way. The reproducibility of mercury determination by using the SS platform modified by electrodeposition from a drop is favorable $(\mathrm{RSD}=2-4 \%$ for $6 \mathrm{ng} \mathrm{Hg}$ ), and this electrodeposition way is suitable for a surface modification. Moreover, the electrodeposition from a drop does not require a special electrochemical cell; handling is simple, the electrolysis spans a short time (35 min for Pd) and the electrochemical coating of the platform dip is ensured. Electrolysis in a drop was therefore selected for all further investigations using SS-ETAAS.

\section{Modifiers and solid environmental samples}

The pyrolytic curves for the determination of mercury in solid environmental samples with a palladium and iridium/gold mixture, applied as a surface treatment to the SS platform, were investigated. A comparison between the use of $\mathrm{Pd}$ electrodeposited from a drop, and the use of Pd after thermal deposition for the determination of mercury in four environmental materials is shown in Fig. 3. The maximum pyrolysis temperature for the analysis of environmental samples according to the pyrolytic curves was in both cases $200^{\circ} \mathrm{C}$. This temperature for solid samples is nearer to the temperature for an aqueous solution on a platform modified by electrodeposition

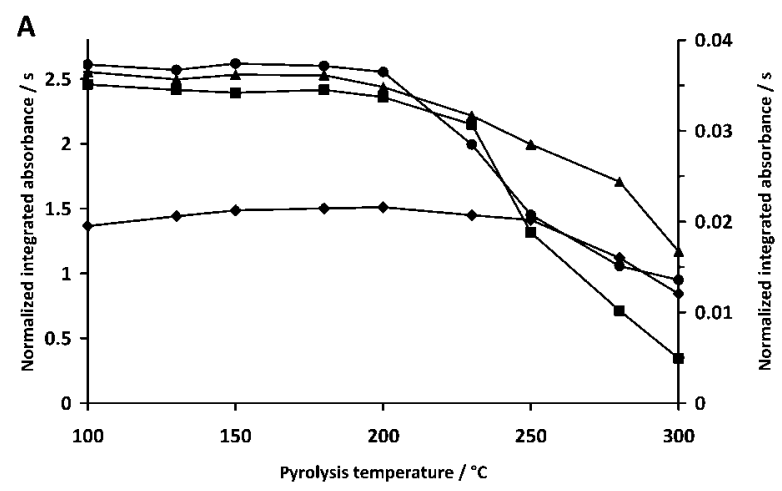

B

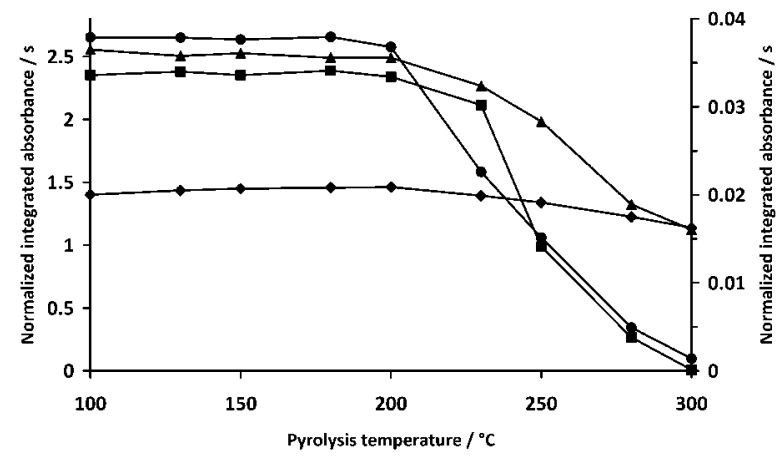

Fig. 3 Pyrolysis curves for the determination of mercury in environmental materials using SS-ETAAS with deuterium background correction: (A) Pd electrodeposited from drop, (B) Pd modifier thermally prepared. To right axe $\mathbf{\square}$, soil I; $\bullet$, GBW; to left axe $\boldsymbol{\Delta}$, plant; $\boldsymbol{O}$, soil II.

from a drop. In the case of an iridium/gold mixture, the results were similar.

\section{Stability of modifiers}

A disadvantage of the iridium/gold mixture modifier is that one component of the mixture, gold, evaporates during atomization cycles, and the second, iridium, remains on the surface of the platform. The vaporization of gold was detected by a temperature of $1700^{\circ} \mathrm{C}$ using a measurement of the $\mathrm{Au}$ absorbance in the cleanout stage. An undesirable preconcentration of iridium on the surface can emerge. From this reason it is suitable to cover the eroded surface of the modified platform with only gold. For better stability of the mercury absorbance, the platform surface was always after 60 - 70 cycles again coated with the modifier. Unfortunately, the spread of gold on the SS platform surface after restoring the surface may be different from the original coating.

Palladium alone was therefore selected as a suitable modifier for the determination of mercury by SS-ETAAS in environmental samples. By using a platform surface modified with Pd, a sensitivity decrease of $10 \%$ was observed after $100-120$ cycles. The platform surface was for that reason always after 100 cycles again coated with $250 \mu \mathrm{g} \mathrm{Pd}$. The stability of modifiers was the same as that for the electrochemical coating as the thermal coating of the SS platform. Similarly, the preparation time for the modification of both platforms was the same, approximately $50 \mathrm{~min}$.

Analytical results

The results obtained for the investigated environmental 
Table 4 Results obtained for Hg in environmental materials using SS-ETAAS with surface modification and calibration against stabilized aqueous standards

\begin{tabular}{lccccc}
\hline \multirow{2}{*}{ Material } & \multicolumn{3}{c}{ Obtained value $\pm \mathrm{SD} / \mathrm{mg} \mathrm{kg}^{-1}(n=6)$} & $\begin{array}{c}\text { Certified and determined } \\
\text { value } \pm \text { SD/mg } \mathrm{kg}^{-1}\end{array}$ \\
\cline { 2 - 5 } & Pd-drop electrodeposition & Pd thermally & Ir/Au-drop electrodeposition & Ir/Au thermally & $0.50 \pm 0.02$ \\
Soil I & $0.48 \pm 0.03$ & $0.48 \pm 0.03$ & $0.52 \pm 0.05$ & $0.49 \pm 0.02$ & $38.1 \pm 0.7$ \\
Soil II & $38.8 \pm 1.6$ & $40.2 \pm 2.5$ & $41.7 \pm 2.9$ & $38.2 \pm 2.8$ & $37.6 \pm 0.5$ \\
Plant & $37.7 \pm 2.0$ & $38.3 \pm 1.6$ & $38.1 \pm 2.0$ & $37.7 \pm 2.1$ & $0.29 \pm 0.03$ \\
GBW 07405 & $0.30 \pm 0.01$ & $0.31 \pm 0.02$ & - & $0.30 \pm 0.01$ & $132 \pm 3$ \\
CRM CC580 & $131 \pm 6$ & $130 \pm 3$ & - & $127 \pm 6$ & \\
\hline
\end{tabular}

samples using SS platforms coated with a palladium or iridium/gold mixture electrolytic from a drop or thermally, and calibration against aqueous standards stabilized by potassium permanganate are given in Table 4. In all cases the results are in good agreement with those obtained by using SS platforms coated thermally, and by measurements with an analyzer (AMA 254) and also with certified values. A separate determination, including weighing and introduction of the platform into the graphite tube, takes approximately $3 \mathrm{~min}$, which means four samples can be analyzed per hour, if five replicates are measured. The detection limit, $120 \mathrm{pg} \mathrm{Hg}$, acquired of 6 repetitive firings of an empty platform makes possible determinations from $1.2 \mathrm{mg} \mathrm{kg}^{-1} \mathrm{Hg}$ for a $0.1 \mathrm{mg}$ sample mass to $0.012 \mathrm{mg} \mathrm{kg}^{-1} \mathrm{Hg}$ for a $10 \mathrm{mg}$ sample mass. By using an optimum sample mass of $0.3 \mathrm{mg}$ the detection limit is $0.4 \mathrm{mg} \mathrm{kg}^{-1} \mathrm{Hg}$.

\section{Conclusion}

Palladium prepared by electrodeposition from a drop of a modifier solution is a suitable modifier for the determination of mercury by SS-ETAAS. A modification of the SS platform surface using electrolysis in a drop is an alternative to thermal deposition. The time of platform modification by the electrochemical procedure in a drop is the same as in case of a seemingly simple thermal coating. Similarly, the sensitivity and the precision of determination are the same. As the advantage of an electrochemical coating, the penetration and transportation of noble metals into the subsurface domain of the graphite are mentioned, ${ }^{22}$ but the stability of the surfaces and the lifetime of both coatings were the same. This process of electrochemical coating of the SS platform surface is promising for the preparation of modifiers, and also for the another purpose, e.g. for the sampling of slurries. Electrodeposition from a drop of a modifier solution can be a simple way to modify the platform surface, and also for SS-ETAAS determinations of other elements. The use of the SS-ETAAS method with a modified surface of the SS platform and calibration against aqueous standards stabilized by potassium permanganate reduces the time of analysis compared with the mercury determination after sample digestion. Sample preparation requires only routine grinding and homogenization. The proposed SS-ETAAS procedure is suitable for the routine monitoring of mercury contents in soils, sediments and plants.

\section{Acknowledgements}

This work was supported by the project MSM 0021622412 of the Ministry of Education, Youth and Sports of the Czech Republic and the project MUNI/A/0992/2009 of Masaryk University in Brno.

\section{References}

1. A. F. da Silva, B. Welz, and A. J. Curtius, Spectrochim. Acta, Part B, 2002, 57, 2031.

2. I. López-García, M. Sánchez-Merlos, and M. HernándezCórdoba, Spectrochim. Acta, Part B, 1997, 52, 2085.

3. C. T. Costley, K. F. Mossop, J. R. Dean, L. M. Garden, J. Marshall, and J. Carroll, Anal. Chim. Acta, 2000, 405, 179.

4. A. Krata and E. Bulska, Spectrochim. Acta, Part B, 2005, 60,345 .

5. E. Bulska, W. Kandler, P. Paslawski, and A. Hulanicki, Mikrochim. Acta, 1995, 119, 137.

6. G. Hall and P. Pelchat, Analyst, 1997, 122, 921.

7. C. E. C. Magalhaes, F. J. Krug, A. H. Fostier, and H. Berndt, J. Anal. At. Spectrom., 1997, 12, 1231.

8. A. Detcheva and K. H. Grobecker, Spectrochim. Acta, Part $B, \mathbf{2 0 0 6}, 61,454$.

9. M. Vale, M. M. Silva, B. Welz, and É. C. Lima, Spectrochim. Acta, Part B, 2001, 56, 1859.

10. A. F. da Silva, F. G. Lepri, D. L. G. Borges, B. Welz, A. J. Curtius, and U. Heitmann, J. Anal. At. Spectrom., 2006, 21, 1321.

11. M. Resano, E. Garcia-Ruiz, M. Aramendia, and M. A. Belarra, J. Anal. At. Spectrom., 2005, 20, 1374.

12. E. Bulska, W. Kandler, and A. Hulanicki, Spectrochim. Acta, Part B, 1996, 51, 1263.

13. I. Kunert, J. Komárek, and L. Sommer, Anal. Chim. Acta, 1979, 106, 285.

14. A. Krata, W. Jedral, and E. Bulska, Spectrochim. Acta, Part B, 2007, 62, 269.

15. D. Q. Zhang, Z. M. Ni, and H. W. Sun, Spectrochim. Acta, Part B, 1998, 53, 1049.

16. P. Bermejo-Barrera, J. Moreda-Piňeiro, A. Moreda-Piňeiro, and A. Bermejo-Barrera, Anal. Chim. Acta, 1994, 296, 181.

17. P. Bermejo-Barrera, M. C. Barciela-Alonso, J. MoredaPiňeiro, C. Gonzáles-Sixto, and A. Bermejo-Barrera, Spectrochim. Acta, Part B, 1996, 51, 1235.

18. D. Baralkiewicz, H. Gramowska, M. Kózka, and A. Kanecka, Spectrochim. Acta, Part B, 2005, 60, 409.

19. D. L. Tsalev, V. I. Slaveykova, L. Lampugnani, A. D'Ulivo, and R. Georgieva, Spectrochim. Acta, Part B, 2000, 55, 473.

20. E. Bulska and W. Jedral, J. Anal. At. Spectrom., 1995, 10, 49.

21. M. Piašcik and E. Bulska, Fresenius J. Anal. Chem., 2001, 370, 1079.

22. E. Bulska, B. Thybusch, and H. M. Ortner, Spectrochim. Acta, Part B, 2001, 56, 363.

23. E. Bulska, M. Piašcik, D. Katskov, N. Darangwa, and M. Grotti, Spectrochim. Acta, Part B, 2007, 62, 1195.

24. M. Konečná and J. Komárek, Spectrochim. Acta, Part B, 2007, 62, 283. 